\title{
Blink reflex changes and sensory perception in infraorbital nerve-innervated areas following zygomaticomaxillary complex fractures
}

\author{
Young Sook Park ${ }^{1}$, Jaehoon Choi ${ }^{2}$, Sang Woo Park ${ }^{3}$ \\ ${ }^{1}$ Department of Physical Medicine and Rehabilitation, Samsung Changwon Hospital, Sungkyunkwan University School of Medicine, \\ Changwon; ${ }^{2}$ Department of Plastic and Reconstructive Surgery, Keimyung University School of Medicine, Daegu; ${ }^{3}$ Department of Plastic and \\ Reconstructive Surgery, Samsung Changwon Hospital, Sungkyunkwan University School of Medicine, Changwon, Korea
}

Background Infraorbital nerve dysfunction is commonly reported after zygomaticomaxillary complex fractures. We evaluated sensory changes in four designated areas (eyelid, nose, zygoma, and lip) innervated by the infraorbital nerve. This evaluation was conducted using the static two-point discrimination test and the vibration threshold test. We assessed the diagnostic significance of the blink reflex in patients with infraorbital nerve dysfunction.

Methods This study included 18 patients, all of whom complained of some degree of infraorbital nerve dysfunction preoperatively. A visual analog scale, the infraorbital blink reflex, static two-point discrimination, and the vibration threshold were assessed preoperatively, at 1 month postoperatively (T1), and at a final follow-up that took place at least 4 months postoperatively (T4). The results were analyzed using a multilevel generalized linear mixed model. Results Scores on the visual analog scale significantly improved at T1 and T4. The infraorbital blink reflex significantly improved at T4. Visual analog scale scores improved more rapidly than the infraorbital blink reflex. Two-point discrimination significantly improved in all areas at $\mathrm{T} 4$, and the vibration perception threshold significantly improved in the eyelid at T4.

Conclusions Recovery of the infraorbital blink reflex reflected the recovery of infraorbital nerve dysfunction. We also determined that the lip tended to recover later than the other areas innervated by the infraorbital nerve.

Keywords Zygomatic fractures / Sensory threshold / Vibration / Blink reflexes
Correspondence: Sang Woo Park Department of Plastic and Reconstructive Surgery, Samsung Changwon Hospital, Sungkyunkwan University School of Medicine, 158 Paryong-ro, Masanhoewon-gu, Changwon 51353, Korea Fax: +82-55-233-5289 E-mail:apexwooo@naver.com

Received: June 24, 2020 • Revised: August 24, $2020 \bullet$ Accepted: September 23, 2020

pISSN: 2234-6163 • elSSN: 2234-6171 • https://doi.org/10.5999/aps.2020.01130 • Arch Plast Surg 2020;47:559-566

\section{INTRODUCTION}

Infraorbital nerve (ION) dysfunction is commonly reported after zygomaticomaxillary complex (ZMC) fractures (in 30.4\%$80 \%$ of cases), as these fractures frequently involve the infraorbital fissure, canal, or foramen [1-5].

ION dysfunction may not recover spontaneously in some pa- tients with severe ZMC fractures; however, spontaneous recovery of the nerve does occur in most cases [6]. However, little data are available concerning sensory change in the areas (lower eyelid, cheek, lateral wall of nose, lip and gingiva/teeth) innervated by the ION. In our experience, at 3-4 months following ZMC fractures, patients often complain about impaired sensory function in the lip despite full recovery in other areas. Therefore,

Copyright (C) 2020 The Korean Society of Plastic and Reconstructive Surgeons

This is an Open Access article distributed under the terms of the Creative Commons Attribution Non-Commercial License (https://creativecommons.org/

licenses/by-nc/4.0/) which permits unrestricted non-commercial use, distribution, and reproduction in any medium, provided the original work is properly cited.

www.e-aps.org 
there are differences in sensory recovery among the areas in which the ION is distributed. Homer et al. [7] assessed sensory changes in the areas along the ION path, but they used only a visual analog scale (VAS) for sensory assessment. However, a limitation of VAS assessments is that they rely on patients' subjective judgment. Therefore, we evaluated sensory changes in four designated areas innervated by the ION using the static two-point discrimination test (TPD) and the vibration perception threshold test.

Trigeminal sensory afferent fibers mediate the blink reflex, as well as their central connections in the trigeminal and facial brainstem nuclei at the level of the lower pons and medulla oblongata [8]. When the skin innervated by the ION is electrically stimulated, the contraction response of the orbicularis oculi muscle via the pontine reflex or pontine and lateral medulla pathway is electromyographically evaluated. Therefore, changes in the compound muscle action potential (CMAP) can be observed when ION sensory afferent fibers are injured. Ohki and Takeuchi [9] reported that the blink reflex is an objective method for evaluating ION injuries, unlike other evaluation methods that depend on patients' verbal responses. For this reason, the blink reflex may be useful in evaluating ION injuries following ZMC fractures. Therefore, our aim was to evaluate the diagnostic significance of the blink reflex in patients with ION dysfunction after ZMC fractures.

\section{METHODS}

\section{Patients}

Subjects with unilateral ZMC fractures who were treated with open reduction and internal fixation with or without orbital floor reconstruction between December 2015 and March 2019 participated in this study. All participants complained of some degree of ION dysfunction preoperatively. This study was approved by the Institutional Review Board of Sungkyunkwan University (IRB No. 2020-06-004). The inclusion criteria encompassed patients who were at least 18 years old and had received at least 4 months of follow-up. The exclusion criteria were patients who had a facial skin injury or associated maxillofacial fractures such as nasal bone fracture, a history or presence of facial nerve palsy, or pregnancy.

\section{Procedure}

All reduction surgery was performed under general anesthesia. All procedures were performed using a lateral eyebrow, subciliary, and intraoral approach and three-point fixation of the zygomaticofrontal suture, infraorbital rim, and zygomaticomaxillary buttress. Titanium plates were used for rigid fixation. The orbital floor was routinely explored and, if necessary, reconstructed using a Medpor porous polyethylene implant (Porex Surgical Inc., Newnan, GA, USA) to restore orbital volume.

\section{Assessment}

All assessments were performed by a physiatrist (YSP) preoperatively (T0), 1 month postoperatively (T1), and at least 4 months postoperatively (T4). The initial assessment was performed on the day before the operation to measure facial swelling reduction as best as possible. The TPD and vibration test were assessed in four designated areas along the ION tract: lower eyelid, cheek, lateral wall of nose, and lip. The gingiva was not tested to prevent the need for lifting the lip, which would affect the assessment and cause patient discomfort. The testing conditions were identical for all subjects.

Patients' subjective sensory function was assessed using a VAS (range, 0-10). A score of 0 denoted normal intensity sensation and 10 represented no sensation.

In the infraorbital blink reflex, the eyelid closes in response to an exteroceptive/nociceptive stimulus to the ION. Patients were asked to close their eyes while in supine position. Active electrodes were placed bilaterally over the orbicularis oculi muscle at the lower eyelids, and a reference electrode was placed on the bilateral temples, lateral to the eye. Stimulating electrodes were pasted on the skin just above the infraorbital foramen. A ground electrode was placed on either the chin or forehead. The stimulation intensity was $20-25 \mathrm{~mA}$ with a duration of $0.1 \mathrm{~ms}$ at a frequency of $0.5 \mathrm{~Hz}$. Nicolet Viking Select (Biomedical, Viasys Neurocare, Madison, WI, USA) was used with settings of sensitivity of $200 \mu \mathrm{V} /$ division, a sweep speed of $10 \mathrm{~ms} /$ division, and a filter at $20-200 \mathrm{~Hz}$. The three recorded responses consisted of an ipsilateral early component (R1) followed by ipsilateral and contralateral late components (R2 and cR2, respectively) (Figs. $1,2)$. Responses were defined as acceptable, prolonged (ipsilateral R1 $\geq 13.1 \mathrm{~ms}$, ipsilateral R2 $\geq 41 \mathrm{~ms}$, or contralateral R2 $\geq 44 \mathrm{~ms}$ ), or no response. An acceptable response was assigned a value of 3 , a prolonged response was assigned a value of 2 , and no response was assigned a value of 1 [10].

To measure the TPD, a Dellon-McKinnon Disk-Criminator (Sammons-Preston Canadian Inc., Mississauga, ON, Canada) was used. The measures were transformed into categorical data as follows: a TPD of 1-5 mm was given a value of 4 , a TPD of 6-10 $\mathrm{mm}$ was given a value of 3 , a TPD of $11-15 \mathrm{~mm}$ was given a value of 2 , and an unmeasurable TPD was given a value of 1 [11].

To measure the vibration perception threshold, an MMD1000A Biothesiometer (Medical Supply Co., Seoul, Korea) was used. The measurements were transformed into categorical data as follows: a vibration perception threshold up to $15 \mathrm{~V}$ was as- 


\section{Fig. 1. Blink reflex test}

(A) Stimulation of the infraorbital nerve: active electrodes on the bilateral lower eyelids, reference electrodes on bilateral temples, and a ground electrode on chin, with stimulation above the infraorbital foramen. (B) Waveform of the infraorbital blink reflex from normal and abnormal patients. R1, ipsilateral early component; R2, ipsilateral late component; cR2, contralateral late component.
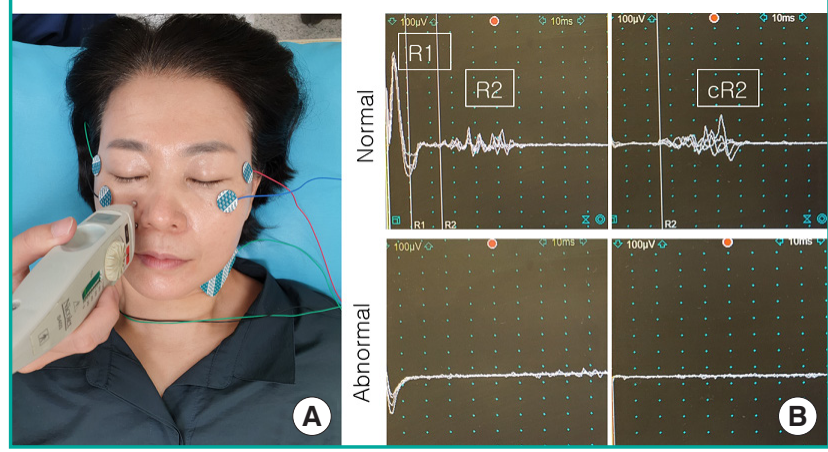

Fig. 2. Schematic representation of the blink reflex pathways

Vmot, trigeminal motor nucleus; Vpr, principal trigeminal nucleus; VI, abducens nucleus; VII, facial nucleus; mid, middle; Tegm, tegmental; R1, ipsilateral early component; R2, ipsilateral late component; $c R 2$, contralateral late component.

\section{Electrical stimulus}

to the inferior orbital nerve

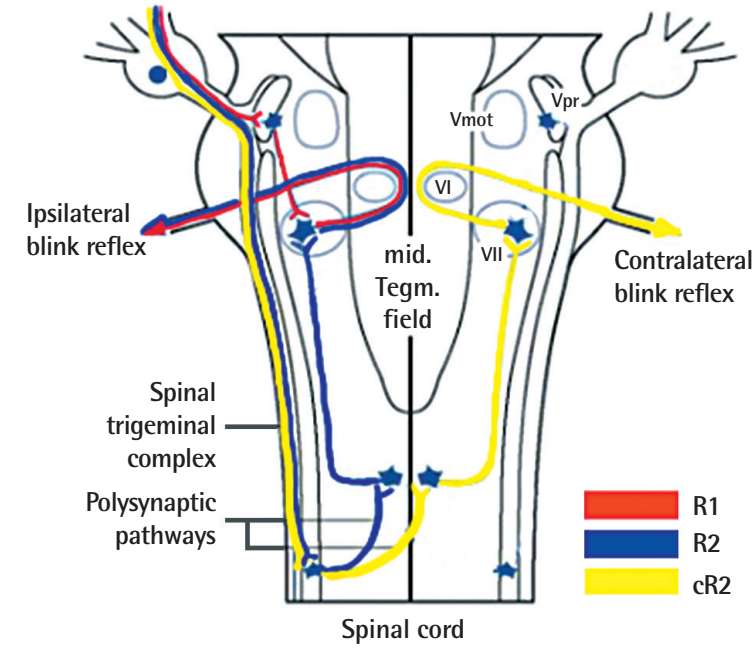

signed a value of 3 , a vibration perception threshold of $16-25 \mathrm{~V}$ was assigned a value of 2 , and a vibration perception threshold of $>25 \mathrm{~V}$ was assigned a value of 1 [12].

\section{Statistical analysis}

The results are presented as mean values. The analysis was performed using a linear mixed effects regression model. All models included the following covariates: sex, age, smoking status, orbital floor reconstruction requirement, and time. If time was
Table 1. Demographic characteristics of patients

\begin{tabular}{|lc|}
\hline Characteristics & Value \\
\hline No. of patients & 18 \\
Mean age (yr) & 44.75 \\
Sex ratio, male/female & $11 / 7$ \\
Side, left/right & $8 / 10$ \\
Smoking & 2 \\
Floor operation & 3 \\
Average follow-up period (mon) & 4.7 \\
\hline
\end{tabular}

significant, Bonferroni-adjusted pairwise comparisons were performed to determine significant changes between periods ( $\mathrm{T} 0$ and $\mathrm{T} 1, \mathrm{~T} 0$ and $\mathrm{T} 4$, and $\mathrm{T} 1$ and $\mathrm{T} 4$ ). Their respective differences and 95\% confidence intervals (CIs) were calculated, and P-values of 0.05 or less were considered to indicate statistical significance. All statistical analyses were performed using Stata version 14.0 (StataCorp, College Station, TX, USA).

\section{RESULTS}

Eighteen of the 109 initially enrolled patients completed the study. Sixty-two of the remaining 91 patients discontinued participation for personal reasons, and 29 did not complete followup. Of the 18 patients who were ultimately analyzed, 11 were men and seven were women (mean age, 44.75 years; range, 1868 years). None of these 18 participants had diabetes mellitus. Two were smokers. Fifteen patients had an isolated ZMC fracture, and three had a ZMC fracture combined with a blow-out fracture. Ten patients had a ZMC fracture on the right side. All patients underwent open reduction and internal fixation. Three of the patients underwent orbital floor reconstruction. The infraorbital foramen and nerve were observed in all cases during surgery, and no ION trapping at the fracture site or any direct ION injury was observed. Following surgery, neither wound infection nor hematoma was observed in any case. All patients were followed up for at least 4 months, with an average of 4.7 months (Table 1).

\section{Visual analog scale}

The average VAS score at T0, T1, and T4 was 2.06, 0.43, and 0.18 , respectively. Preoperatively, all patients had a VAS score of less than 5 , and three patients had normal sensation. VAS scores were only significantly influenced by time. The VAS assessments at $\mathrm{T} 1$ (estimated difference, $-1.63 ; 95 \% \mathrm{CI}$ for difference, -2.19 to -1.06 ) and T4 (estimated difference, -1.88 ; 95\% CI for difference, -2.44 to -1.31 ) reflected significant improvements compared to T0. VAS scores significantly improved starting 1 month postoperatively. At the final follow-up, 16 patients had normal 
Table 2. Mean VAS, infraorbital blink reflex, static two-point discrimination, and vibration perception threshold scores

\begin{tabular}{|c|c|c|c|c|c|c|c|c|c|c|c|c|}
\hline \multirow{2}{*}{ Time } & \multirow{2}{*}{ VAS } & \multicolumn{3}{|c|}{ Infraorbital blink reflex } & \multicolumn{4}{|c|}{ Static two-point discrimination } & \multicolumn{4}{|c|}{ Vibration perception threshold } \\
\hline & & R1 & $\mathrm{R} 2$ & $\mathrm{cR} 2$ & Eyelid & Nose & Zygoma & Lip & Eyelid & Nose & Zygoma & Lip \\
\hline TO & 2.06 & 2.25 & 2.31 & 2.31 & 1.81 & 2.00 & 1.75 & 2.12 & 2.62 & 2.68 & 2.68 & 2.81 \\
\hline T1 & 0.43 & 2.37 & 2.43 & 2.43 & 2.31 & 2.12 & 2.31 & 2.75 & 2.81 & 2.87 & 2.75 & 2.75 \\
\hline T4 & 0.18 & 2.75 & 2.81 & 2.81 & 2.37 & 2.56 & 2.56 & 2.81 & 3.00 & 2.93 & 2.75 & 2.87 \\
\hline
\end{tabular}

VAS score of 0 denoted normal intensity sensation and 10 represented no sensation.

VAS, visual analog scale; T0, preoperatively; T1, 1 month postoperatively; T4, at least 4 months postoperatively; R1, ipsilateral early component; R2, ipsilateral late component; cR2, contralateral late component.

Table 3. Significance of covariates for the visual analog scale

\begin{tabular}{|lcc|}
\hline Variable & Coefficient \pm SE & P-value \\
\hline Sex & $-0.57 \pm 0.34$ & 0.097 \\
Age & $-0.01 \pm 0.01$ & 0.521 \\
Smoking & $0.53 \pm 0.67$ & 0.429 \\
Floor operation & $0.52 \pm 0.41$ & 0.210 \\
Time & $-0.94 \pm 0.14$ & $<0.001^{\text {a) }}$ \\
\hline SE, standard error. & & \\
alP $<0.05$. & & \\
\hline
\end{tabular}

sensation, and two patients had VAS scores of 1 and 2, respectively. All patients showed VAS improvement (Tables 2-4).

\section{Infraorbital blink reflex}

The infraorbital blink reflex on the nonfractured side was normal in all patients. Preoperatively, 11 patients had acceptable R1, $R 2$, and cR2; five had no response on R1, R2, and cR2; one had prolonged R1, R2, and CR2; and one had prolonged R1 and acceptable R2 and cR2. These findings indicate that even though most patients complained of ION dysfunction preoperatively, 11 (61\%) had no significant ION injury. The infraorbital blink reflex was significantly influenced only by time. R1, R2, and cR2 at time 4 were significantly larger than at T0 (estimated difference, 0.50 ; 95\% CI for difference, 0.06 to 0.94 ). R1, R2, and cR2 significantly improved at 4 months postoperatively. At the final follow-up, only three patients (16\%) had abnormal R1, R2, and cR2 (Tables 2, 5, 6).

\section{Static two-point discrimination}

On the nonfractured side, TPD showed no significant change over time. The eyelid TPD was significantly influenced by sex, smoking status, and time. The nasal TPD was significantly influenced by sex and time. The zygomatic TPD was significantly influenced by smoking status and time. The lip TPD was significantly influenced by orbital floor reconstruction and time. The value of TPD at T4 was significantly higher than that at time 0 in all areas (eyelid: estimated difference, 0.56; 95\% CI for difference, 0.03 to 1.09 ; nose: estimated difference, 0.56 ; $95 \% \mathrm{CI}$ for
Table 4. Sample estimates and standard deviations for VAS scores by time

\begin{tabular}{|c|c|c|c|}
\hline Time & Mean \pm SD & $\begin{array}{c}\mathrm{T} 1, \\
\text { mean difference } \\
(95 \% \mathrm{Cl})\end{array}$ & $\begin{array}{c}\text { T4, } \\
\text { mean difference } \\
(95 \% \mathrm{Cl})\end{array}$ \\
\hline TO & $2.06 \pm 1.34$ & $-1.63(-2.19,-1.06)^{a)}$ & $-1.88(-2.44,-1.31)^{\mathrm{a})}$ \\
\hline $\mathrm{T} 1$ & $0.44 \pm 0.73$ & & $-0.25(-0.81,0.31)$ \\
\hline T4 & $0.19 \pm 0.54$ & & \\
\hline \multicolumn{4}{|c|}{$\begin{array}{l}\text { VAS score of } 0 \text { denoted normal intensity sensation and } 10 \text { represented no } \\
\text { sensation. } \\
\text { VAS, visual analog scale; T0, preoperatively; } \mathrm{T} 1,1 \text { month postoperatively; } \mathrm{T} 4 \text {, at } \\
\text { least } 4 \text { months postoperatively; } \mathrm{Cl} \text {, confidence interval. } \\
\text { a) } P<0.05 \text {. }\end{array}$} \\
\hline
\end{tabular}

difference, 0.14 to 0.98 ; zygoma: estimated difference, $0.81 ; 95 \%$ CI for difference, 0.25 to 1.38; lip: estimated difference, 0.69; $95 \% \mathrm{CI}$ for difference, 0.11 to 1.26 ). The value of TPD at T1 was significantly higher than that at T0 in the lip (estimated difference, 0.63 ; $95 \%$ CI for difference, 0.05 to 1.20 ) (Tables 2, 7, 8).

\section{Vibration perception threshold}

On the nonfractured side, the vibration perception threshold showed no significant change over time. In the eyelid and nose, the vibration perception threshold was significantly influenced by time. In the zygoma and lip, the vibration perception threshold was significantly influenced by the requirement for orbital floor reconstruction. The value of the vibration perception threshold at T4 was significantly higher than that at T0 in the eyelid (estimated difference, 0.38 ; $95 \%$ CI for difference, 0.09 to 0.66) (Tables 2, 9, 10).

\section{DISCUSSION}

In the infraorbital blink reflex, the afferent portion of the blink reflex is supplied by the ION, and the efferent volleys are conducted by branches of the facial nerve that innervate the orbicularis oculi muscle. When the skin innervated by the ION is electrically stimulated, a CMAP from the surface of the orbicularis oculi muscle is recorded. When the ION is injured, a change in 
Table 5. Significance of covariates for the infraorbital blink reflex

\begin{tabular}{|c|c|c|c|c|c|c|}
\hline \multirow{2}{*}{ Variable } & \multicolumn{2}{|c|}{$\mathrm{R} 1$} & \multicolumn{2}{|c|}{$\mathrm{R} 2$} & \multicolumn{2}{|c|}{ cR2 } \\
\hline & Coefficient \pm SE & P-value & Coefficient \pm SE & P-value & Coefficient \pm SE & P-value \\
\hline Sex & $0.53 \pm 0.34$ & 0.109 & $0.60 \pm 0.32$ & 0.060 & $0.60 \pm 0.32$ & 0.060 \\
\hline Age & $0.00 \pm 0.01$ & 0.985 & $-0.01 \pm 0.01$ & 0.483 & $-0.01 \pm 0.01$ & 0.483 \\
\hline Smoking & $0.37 \pm 0.66$ & 0.568 & $0.37 \pm 0.63$ & 0.557 & $0.37 \pm 0.63$ & 0.557 \\
\hline Floor operation & $0.07 \pm 0.40$ & 0.869 & $0.02 \pm 0.39$ & 0.959 & $0.02 \pm 0.39$ & 0.959 \\
\hline Time & $0.25 \pm 0.09$ & $0.007^{\mathrm{a})}$ & $0.25 \pm 0.09$ & $0.007^{\mathrm{a})}$ & $0.25 \pm 0.09$ & $0.007^{\mathrm{a})}$ \\
\hline
\end{tabular}

Table 6. Sample estimates and standard deviations for infraorbital blink reflex by time

\begin{tabular}{|c|c|c|c|c|}
\hline Time & & Mean \pm SD & T1, mean difference $(95 \% \mathrm{Cl})$ & T4, mean difference $(95 \% \mathrm{CI})$ \\
\hline \multirow[t]{3}{*}{ R1 } & T0 & $2.25 \pm 0.93$ & $0.13(-0.31,0.56)$ & $0.50(0.06,0.94)^{a}$ \\
\hline & $\mathrm{T} 1$ & $2.38 \pm 0.89$ & & $0.38(-0.06,0.81)$ \\
\hline & $\mathrm{T} 4$ & $2.75 \pm 0.58$ & & \\
\hline \multirow[t]{3}{*}{ R2 } & T0 & $2.31 \pm 0.95$ & $0.13(-0.31,0.56)$ & $0.50(0.06,0.94)^{a}$ \\
\hline & $\mathrm{T} 1$ & $2.44 \pm 0.89$ & & $0.38(-0.06,0.81)$ \\
\hline & $\mathrm{T} 4$ & $2.81 \pm 0.54$ & & \\
\hline \multirow[t]{3}{*}{ cR2 } & T0 & $2.31 \pm 0.95$ & $0.13(-0.31,0.56)$ & $0.50(0.06,0.94)^{a}$ \\
\hline & $\mathrm{T} 1$ & $2.44 \pm 0.89$ & & $0.38(-0.06,0.81)$ \\
\hline & $\mathrm{T} 4$ & $2.81 \pm 0.54$ & & \\
\hline
\end{tabular}

Table 7. Significance of covariates for static two-point discrimination

\begin{tabular}{|c|c|c|c|c|c|c|c|c|}
\hline \multirow{2}{*}{ Variable } & \multicolumn{2}{|l|}{ Eyelid } & \multicolumn{2}{|c|}{ Nose } & \multicolumn{2}{|c|}{ Zygoma } & \multicolumn{2}{|l|}{ Lip } \\
\hline & Coefficient \pm SE & P-value & Coefficient \pm SE & P-vlaue & Coefficient \pm SE & P-value & Coefficient \pm SE & P-value \\
\hline Sex & $0.73 \pm 0.20$ & $<0.001^{\text {a) }}$ & $1.01 \pm 0.33$ & $0.002^{\mathrm{a})}$ & $0.42 \pm 0.21$ & 0.053 & $0.36 \pm 0.29$ & 0.216 \\
\hline Age & $-0.01 \pm 0.01$ & 0.192 & $0.01 \pm 0.01$ & 0.130 & $0.01 \pm 0.01$ & 0.146 & $-0.00 \pm 0.01$ & 0.969 \\
\hline Smoking & $1.12 \pm 0.40$ & $0.005^{a)}$ & $0.42 \pm 0.65$ & 0.517 & $0.87 \pm 0.42$ & $0.040^{\mathrm{a})}$ & $0.88 \pm 0.58$ & 0.127 \\
\hline Floor operation & $0.29 \pm 0.25$ & 0.242 & $-0.72 \pm 0.40$ & 0.071 & $-0.19 \pm 0.26$ & 0.471 & $-0.77 \pm 0.36$ & $0.031^{a)}$ \\
\hline Time & $0.28 \pm 0.11$ & $0.012^{\mathrm{a})}$ & $0.28 \pm 0.09$ & $0.002^{\mathrm{a})}$ & $0.41 \pm 0.12$ & $0.001^{\text {a) }}$ & $0.34 \pm 0.12$ & $0.005^{\mathrm{a})}$ \\
\hline
\end{tabular}

the CMAP can be observed. ZMC fractures are commonly accompanied by ION dysfunction. Therefore, in patients with ZMC fractures, the presence of an abnormal infraorbital blink reflex may indicate nerve injury along the ION-facial nerve pathway.

The CMAP is normally composed of three responses: R1, R2, and $\mathrm{CR} 2$. The $\mathrm{R} 1$ response is mediated by an oligosynaptic pontine circuit. The $\mathrm{R} 2$ and $\mathrm{cR} 2$ components result from activation of a polysynaptic chain of brain stem interneurons extending in the lateral reticular formation at the pontine and medullar level $[8,13]$. Because the circuit of $\mathrm{R} 1$ is shorter than that of $\mathrm{R} 2$ and
$\mathrm{cR} 2, \mathrm{R} 1$ is recorded earlier than $\mathrm{R} 2$ and $\mathrm{cR} 2$. The efferent volley of the $\mathrm{R} 2$ response involves the ipsilateral facial nerve, but that of the $\mathrm{CR} 2$ involves the contralateral facial nerve. Therefore, when the ION is injured, R1, R2, and cR2 may show similar changes because the afferent portions are in the ION. In our study, six patients with an abnormal infraorbital blink reflex had identical grades of R1, R2, and cR2. However, one patient had prolonged R1 and acceptable R2 and cR2. Recently, Ohki and Takeuchi [9] noted that R1 and R2 may be mediated by different sensory nerve fibers: R1 by A- $\beta$ fibers and R 2 by A- $\beta$ and $A-\delta$ fibers. The thickest type of fiber is A- $\alpha$, followed in descend- 
Table 8. Sample estimates and standard deviations for static two-point discrimination by time

\begin{tabular}{|c|c|c|c|c|}
\hline Time & & Mean $\pm S D$ & $\mathrm{~T} 1$, mean difference $(95 \% \mathrm{CI})$ & T4, mean difference $(95 \% \mathrm{Cl})$ \\
\hline \multirow[t]{3}{*}{ Eyelid } & TO & $1.81 \pm 0.91$ & $0.50(-0.03,1.03)$ & $0.56(0.03,1.09)^{\mathrm{a})}$ \\
\hline & $\mathrm{T} 1$ & $2.31 \pm 0.79$ & & $0.06(-0.47,0.59)$ \\
\hline & $\mathrm{T} 4$ & $2.38 \pm 0.72$ & & \\
\hline \multirow[t]{3}{*}{ Nose } & TO & $2.00 \pm 1.03$ & $0.13(-0.29,0.54)$ & $\left.0.56(0.14,0.98)^{a}\right)$ \\
\hline & $\mathrm{T} 1$ & $2.13 \pm 1.02$ & & $0.44(0.02,0.86)^{a)}$ \\
\hline & $\mathrm{T} 4$ & $2.56 \pm 1.03$ & & \\
\hline \multirow[t]{3}{*}{ Zygoma } & TO & $1.75 \pm 0.93$ & $0.56(-0.00,1.13)$ & $0.81(0.25,1.38)^{\mathrm{a})}$ \\
\hline & $\mathrm{T} 1$ & $2.31 \pm 0.79$ & & $0.25(-0.31,0.81)$ \\
\hline & T4 & $2.56 \pm 0.63$ & & \\
\hline \multirow[t]{3}{*}{ Lip } & TO & $2.13 \pm 1.02$ & $0.63(0.05,1.20)^{a}$ & $0.69(0.11,1.26)^{a)}$ \\
\hline & $\mathrm{T} 1$ & $2.75 \pm 0.93$ & & $0.06(-0.51,0.64)$ \\
\hline & T4 & $2.81 \pm 0.83$ & & \\
\hline
\end{tabular}

Table 9. Significance of covariates for the vibration perception threshold

\begin{tabular}{|c|c|c|c|c|c|c|c|c|}
\hline \multirow{2}{*}{ Vairable } & \multicolumn{2}{|c|}{ Eyelid } & \multicolumn{2}{|l|}{ Nose } & \multicolumn{2}{|c|}{ Zygoma } & \multicolumn{2}{|c|}{ Lip } \\
\hline & Coefficient \pm SE & P-value & Coefficient \pm SE & P-value & Coefficient \pm SE & P-value & Coefficient \pm & P-value \\
\hline Sex & $0.11 \pm 0.12$ & 0.367 & $0.15 \pm 0.11$ & 0.200 & $-0.23 \pm 0.15$ & 0.115 & $-0.01 \pm 0.10$ & 0.937 \\
\hline Age & $0.00 \pm 0.00$ & 0.690 & $0.00 \pm 0.00$ & 0.446 & $0.01 \pm 0.00$ & 0.106 & $-0.00 \pm 0.00$ & 0.618 \\
\hline Smoking & $0.11 \pm 0.23$ & 0.636 & $0.05 \pm 0.23$ & 0.815 & $0.14 \pm 0.29$ & 0.616 & $0.11 \pm 0.20$ & 0.586 \\
\hline Floor operation & $-0.13 \pm 0.14$ & 0.352 & $-0.15 \pm 0.14$ & 0.276 & $-0.70 \pm 0.18$ & $<0.001^{\text {a) }}$ & $-0.58 \pm 0.12$ & $<0.001^{\mathrm{a}}$ \\
\hline Time & $0.19 \pm 0.06$ & $0.001^{\mathrm{a})}$ & $0.13 \pm 0.06$ & $0.033^{\mathrm{a})}$ & $0.03 \pm 0.04$ & 0.476 & $0.03 \pm 0.06$ & 0.572 \\
\hline
\end{tabular}

Table 10. Sample estimates and standard deviations for the vibration perception threshold by time

\begin{tabular}{|c|c|c|c|c|}
\hline Time & & Mean \pm SD & $\mathrm{T} 1$, mean difference $(95 \% \mathrm{CI})$ & T4, mean difference $(95 \% \mathrm{Cl})$ \\
\hline \multirow[t]{3}{*}{ Eyelid } & TO & $2.63 \pm 0.50$ & $0.19(-0.09,0.47)$ & $0.38(0.09,0.66)^{\mathrm{a})}$ \\
\hline & $\mathrm{T} 1$ & $2.81 \pm 0.40$ & & $0.19(-0.09,0.47)$ \\
\hline & $\mathrm{T} 4$ & $3.00 \pm 0.00$ & & \\
\hline \multirow[t]{3}{*}{ Nose } & T0 & $2.69 \pm 0.48$ & $0.19(-0.09,0.47)$ & $0.25(-0.03,0.53)$ \\
\hline & $\mathrm{T} 1$ & $2.88 \pm 0.34$ & & $0.06(-0.22,0.34)$ \\
\hline & T4 & $2.94 \pm 0.25$ & & \\
\hline \multirow[t]{3}{*}{ Zygoma } & T0 & $2.69 \pm 0.48$ & $0.06(-0.15,0.27)$ & $0.06(-0.15,0.27)$ \\
\hline & $\mathrm{T} 1$ & $2.75 \pm 0.45$ & & $0.00(-0.21,0.21)$ \\
\hline & T4 & $2.75 \pm 0.45$ & & \\
\hline \multirow[t]{3}{*}{ Lip } & T0 & $2.81 \pm 0.40$ & $-0.06(-0.32,0.20)$ & $0.06(-0.20,0.32)$ \\
\hline & $\mathrm{T} 1$ & $2.75 \pm 0.45$ & & $0.13(-0.14,0.39)$ \\
\hline & T4 & $2.88 \pm 0.34$ & & \\
\hline
\end{tabular}

ing order by $\mathrm{A}-\beta, \mathrm{A}-\delta$, and $\mathrm{C}$. Thicker fibers are more susceptible to compression or inflammation [14]; thus, the fibers related to R1 may be more fragile [9]. Therefore, we expected abnormal $\mathrm{R} 1$ to be more sensitive to ION injuries. However, we did not observe a significant difference between R1, R2, and cR2.

Preoperatively, on the VAS, three patients had normal sensa- tion, and 15 patients had paresthesia. Seven patients had an abnormal infraorbital blink reflex, indicating nerve damage more severe than neurapraxia, as patients with an abnormal blink reflex might have more severe symptoms than patients with a normal blink reflex. Therefore, although 15 patients complained of some degree of ION dysfunction, only seven (46\%) of these pa- 
tients had nerve damage identified in the infraorbital blink study. Recovery of the VAS scores required less time than that of the infraorbital blink reflex. Compared to the preoperative results, the VAS significantly improved at 1 month postoperatively, while the infraorbital blink reflex significantly improved by the final follow-up.

In our experience, many patients complained about affected sensory perception in the lip despite normal sensation in other areas. Nerve recovery is better after distal injuries than after proximal ones [15]. The lip is the farthest distance from inferior orbital canal or foramen. These structures are commonly damaged by ZMC fractures that disrupt the ION-mediated innervation of target organs. Therefore, we predicted that the lip would show the latest sensory recovery of the studied structures. Our results showed that vibration perception threshold of the lip had not improved by the final follow-up, but TPD of the lip had significantly improved. Gelberman et al. [16] reported that threshold tests such as the vibration and Semmes-Weinstein monofilament tests consistently better reflected gradual changes in nerve function than innervation density tests like TPD and moving TPD. Therefore, sensory recovery of the lip tends to occur later than that in other areas innervated by the ION.

Age is a factor contributing to peripheral nerve recovery, which is usually slow and partial in patients older than 50 years $[17,18]$. However, in our study, age did not have an influence on recovery from ION injury. This may be a result of the small number of patients included or the fact that only mild ION injuries were analyzed. In our study, most patients had recovered from ION dysfunction within 16 weeks. Therefore, most patients included in our study did not have more severe nerve injury than neuropraxia. When a nerve is injured mildly, as in these cases, nerve recovery may not be influenced by age. We hypothesized that ZMC fractures accompanied by inferior orbital wall fractures would show slower sensory recovery than $\mathrm{ZMC}$ fractures alone, since the ION is routed in the floor of the orbit. However, when the TPD and vibration perception threshold were assessed in four designated areas along the ION pathway, only the lip was influenced by inferior orbital wall fracture. Homer at al. reported that patients with isolated floor fractures noted long-term numbness in the cheek only, suggesting that the permanent injury was isolated to a single ION branch $[7,19]$. Therefore, inferior orbital wall fractures have a high probability of causing nonselective injuries of a single ION branch.

Our study has several limitations. First, the sample size of the present study was insufficient to ensure the validity of the findings. Although 109 patients were enrolled in our study, only 18 completed the study. This may result from the long measure- ment duration of 15 to 20 minutes for blink testing, which can be difficult in long-term follow-up. Some people experienced discomfort from the electrical stimulus. Second, the average follow-up period was 4.7 months; this may not have permitted time for neural regeneration, which may take more than 6 months postinjury [20]. However, at the last follow-up examination, most patients had recovered from ION damage. Therefore, the assessment of sensory recovery was not an issue. Third, we did not assess the possible association between ION dysfunction and the ZMC fracture pattern, which should be investigated in future studies.

The blink reflex test is an electrophysiological technique that is used to assist in the evaluation of patients with suspected trigeminal or facial nerve disorders or demyelinating polyradiculopathies [8,21-24]. Ohki and Takeuchi [9] evaluated the objectivity of the infraorbital blink reflex in patients with maxillary lesions and concluded that the infraorbital blink reflex is an objective method for evaluating ION injuries. Therefore, we used the blink reflex as an objective and quantitative method to evaluate ION injuries following ZMC fractures, and we demonstrated that the infraorbital blink reflex reflected the recovery of ION dysfunction.

\section{NOTES}

\section{Conflict of interest}

No potential conflict of interest relevant to this article was reported.

\section{Ethical approval}

The study was approved by the Institutional Review Board of Sungkyunkwan University (IRB No. 2020-06-004) and performed in accordance with the principles of the Declaration of Helsinki. Written informed consents were obtained.

\section{Patient consent}

The patient provided written informed consent for the publication and the use of her image.

\section{Author contribution}

Conceptualization: SW Park. Data curation: YS Park, SW Park. Formal analysis: YS Park, J Choi, SW Park. Funding acquisition: J Choi, SW Park. Methodology: YS Park, J Choi, SW Park. Project administration: YS Park, SW Park. Writing - original draft: YS Park. Writing - review \& editing: YS Park, J Choi, SW Park. Approval of final manuscript: all authors. 


\section{ORCID}

Young Sook Park

https://orcid.org/0000-0003-2752-7120

Jaehoon Choi

https://orcid.org/0000-0001-7802-1272

Sang Woo Park

\section{REFERENCES}

1. Nordgaard JO. Persistent sensory disturbances and diplopia following fractures of the zygoma. Arch Otolaryngol 1976; 102:80-2.

2. Balle V, Christensen PH, Greisen O, et al. Treatment of zygomatic fractures: a follow-up study of 105 patients. Clin Otolaryngol Allied Sci 1982;7:411-6.

3. Kristensen S, Tveteras K. Zygomatic fractures: classification and complications. Clin Otolaryngol Allied Sci 1986;11: 123-9.

4. Westermark A, Jensen J, Sindet-Pedersen S. Zygomatic fractures and infraorbital nerve disturbances: miniplate osteosynthesis vs. other treatment modalities. Oral Surg Oral Diagn 1992;3:27-30.

5. Schultze-Mosgau S, Erbe M, Rudolph D, et al. Prospective study on post-traumatic and postoperative sensory disturbances of the inferior alveolar nerve and infraorbital nerve in mandibular and midfacial fractures. J Craniomaxillofac Surg 1999;27:86-93.

6. Neovius E, Fransson M, Persson C, et al. Long-term sensory disturbances after orbitozygomatic fractures. J Plast Reconstr Aesthet Surg 2017;70:120-6.

7. Homer N, Glass LR, Lee NG, et al. Assessment of infraorbital hypesthesia following orbital floor and zygomaticomaxillary complex fractures using a novel sensory grading system. Ophthalmic Plast Reconstr Surg 2019;35:53-5.

8. Kimura J. The blink reflex as a clinical test. In: Aminoff MJ, editor. Electrodiagnosis in clinical neurology. 4th ed. Philadelphia: Churchill Livingstone; 1999. p. 337.

9. Ohki M, Takeuchi N. Objective evaluation of infraorbital nerve involvement in maxillary lesions by means of the blink reflex. Arch Otolaryngol Head Neck Surg 2002;128:952-5.

10. Pyo S, Park YG, Park J, et al. The role of blink reflex in predicting the recovery of facial palsy. J Korean Assoc EMG Electrodiagn Med 2018;20:7-13.

11. Temple CL, Tse R, Bettger-Hahn M, et al. Sensibility fol-

lowing innervated free TRAM flap for breast reconstruction. Plast Reconstr Surg 2006;117:2119-27.

12. Abhilash P, Manasa M, Subrahmanyam BS, et al. Efficacy of epalrestat, duloxetine and epalrestat in combination with methylcobalamine in diabetic peripheral neuropathy. Rom J Diabetes Nutr Metab Dis 2016;23:361-7

13. Aramideh M, Ongerboer de Visser BW. Brainstem reflexes: electrodiagnostic techniques, physiology, normative data, and clinical applications. Muscle Nerve 2002;26:14-30.

14. Cruccu G, Inghilleri M, Fraioli B, et al. Neurophysiologic assessment of trigeminal function after surgery for trigeminal neuralgia. Neurology 1987;37:631-8.

15. Scheib J, Hoke A. Advances in peripheral nerve regeneration. Nat Rev Neurol 2013;9:668-76.

16. Gelberman RH, Szabo RM, Williamson RV, et al. Sensibility testing in peripheral-nerve compression syndromes: an experimental study in humans. J Bone Joint Surg Am 1983;65: 632-8.

17. Mermans JF, Franssen BB, Serroyen J, et al. Digital nerve injuries: a review of predictors of sensory recovery after microsurgical digital nerve repair. Hand (NY) 2012;7:233-41.

18. Song SH, Kwon H, Oh SH, et al. Open reduction of zygoma fractures with the extended transconjunctival approach and T-bar screw reduction. Arch Plast Surg 2018;45:325-32.

19. Kim YH, Choi M, Kim JW. Are titanium implants actually safe for magnetic resonance imaging examinations? Arch Plast Surg 2019;46:96-7.

20. Das AK, Bandopadhyay M, Chattopadhyay A, et al. Clinical evaluation of neurosensory changes in the infraorbital nerve following surgical management of zygomatico-maxillary complex fractures. J Clin Diagn Res 2015;9:ZC54-8.

21. Kennelly KD. Electrophysiological evaluation of cranial neuropathies. Neurologist 2006;12:188-203.

22. Sommerauer L, Engelmann S, Ruewe M, et al. Effects of electrostimulation therapy in facial nerve palsy. Arch Plast Surg 2020 Sep 25 [Epub]. https://doi.org/10.5999/aps.2020.01025.

23. Campodonico A, Pangrazi PP, De Francesco F, et al. Reconstruction of a long defect of the median nerve with a free nerve conduit flap. Arch Plast Surg 2020;47:187-93.

24. Oh TS, Kim HB, Choi JW, et al. Facial reanimation with masseter nerve-innervated free gracilis muscle transfer in established facial palsy patients. Arch Plast Surg 2019;46:122-8. 